\title{
Multinational OCEANOGRAPHIC COOPERATION
}

\author{
By Muriel Cole
}

\begin{abstract}
"W things would fall apart," Ants Leetmaa told me recently, referring to the joint efforts of the U.S., Japan, Korea, and others in developing and maintaining the TOGA TAO Array. The extent to which international cooperation benefits us is not always obvious nor is how it works. There is an untold number of acronyms, groups, and programs, which sometimes overlap in purpose, providing healthy competition at best, redundancy at worst.
\end{abstract}

\section{Why Is International Cooperation Important?}

Working cooperatively with other countries is costly and time consuming. It can seem thankless. Progress can be slow to those of us used to the efficiency and instant gratification of push button surroundings. Yet no single country has ever been or will ever be able to incur the cost of doing global oceanography. So it is not only in our best interest, but it is essential to foster activities with other countries. This cooperation is not limited to blue water oceanography. Many societal concerns in coastal regions are common to many countries. Assessing the global magnitude and rate of change in nonpoint source pollution requires comparable coastal data from many countries, for example. Coastal problems of concern in a region require multinational data. International standards and measurement and exchange techniques also need to be developed and implemented. A description and evaluation of the state of coral reef ecosystems cannot be made without agreed upon methodologies, for example.

Muriel Cole, International Affairs Specialist, National Ocean Services, NOAA. 1305 East-West Highway, Silver Spring, Maryland 20910, USA.
So Exactly Who Does This and How?

We as a community do this. It is not someone else. Basically there are two avenues: the intergovernmental and the nongovernmental. The intergovernmental, made up at the policy level of representatives of 125 countries, is the Intergovernmental Oceanographic Commission (IOC) of UNESCO. The nongovernmental is the International Council of Scientific Unions, with its Scientific Committee on Oceanic Research (SCOR), and its programs such as the International Geosphere Biosphere Program.

\section{IOC REGIONAL PROGRAMMES}

IOCARIBE-Subcommission for the Caribbean and Adjacent Regions

WESTPAC-Subcommission for the Western Pacific

IOCEA-Regional Committee for the Central Eastern Atlantic

IOCINCWIO-Regional Committee for the Cooperative Investigation in the North and Central Western Indian Ocean

IOCINDIO-Regional Committee for the Central Indian Ocean

IOCSOC-Regional Committee for the Southern Ocean

The Intergovernmental Oceanographic Commission

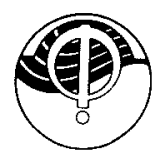

The IOC was founded in 1960 to develop and coordinate international programs for scientific investigation of the oceans and related services. The commission's work is carried out through a large number of committees and expert groups, with a small full time staf in Paris, the site of UNESCO Headquarters. In recent years the IOC has become more focused on coastal problems and is attempting to strengthen its regional activities in places such as the Western Pacific and Caribbean. As the field of oceanography matures, the IOC's focus is also shifting toward the applications of science for socioeconomic benefit. The Commission is a catalyst to stimulate and coordinate a range of specific assistance activities. IOC also advises other international agencies on how to help increase marine science capabilities within developing countries.

\section{How Is International Oceanography Funded?}

It is important to note that the work of the IOC is the sum of the work of all of its member countries. The IOC fosters this work, but most of its small budget is used to pay travel costs of experts and representatives of developing countries. To an increasing extent, the IOC has been asked to carry out more activities than can effectively be done with the resources available. Although an increase in the present U.S. voluntary contribution of $\$ 500,000$ per year has repeatedly been sought, the amount of funding has remained stable for several years. As with other federal expenditures, the U.S contribution to U.N. programs is now undergoing unprecedented scrutiny. The U.S. will not likely be able to continue its present level of financial support to the IOC beyond 1995.

\section{Who Decides What Is Important?}

Every two years senior member state representatives attend the IOC Assembly. The most recent assembly was held in June 1995. Over the course of two weeks participants debate a wide variety of topics. For example, in June the Assembly addressed the progress in implementing a 
Global Ocean Observing System, access to EEZ for research purposes, and the level of authority of the IOC within UNESCO. The Assembly approved a number of actions including a meeting to be hosted by the U.S. in May 1996 to reach agreement among countries on specific GOOS activities, a marine biodiversity pilot project, a Black Sea Regional Committee, and preparatory work for the 1998 International Year of the Ocean.

\section{How Does One Get Involved In International Efforts?}

IOC activities are supported and carried out at national levels. Expert groups develop standards, prepare as- sessments, identify scientific requirements, etc., and are funded by those countries which are particularly interested in the work. Most scientists are paid for travel only. The following list provides examples of IOC programs and points of contact:

- Integrated Global Ocean Services System

Chairman, Dieter Kohnke

Internet: dieter.kohnke@M4.hamburg. bsh.d400.de

- Global Sea Level Observing System Chairman, David Pugh Internet: dtp@ua.nwo.ac.uk

- International Oceanographic Data and Information Exchange
Chairman: Ron Wilson

Internet: wilson@ottmed.meds.dfo.ca

- Tsunami Warning System in the Pacific Chairman: Capt. Hugo Gorziglia Internet: shoa@huelen.reuna.cl

- Global Investigation of Pollution in the Marine Environment Chairman: Neil Andersen Internet: andersen@hpel.umd.gov

- Global Ocean Observing System Contact: GOOS Support Office, IOC Internet: j.rebert@unesco.org

The following article by Elizabeth Gross and Terry Healy describes the role of Scientific Committee on Oceanic Research (SCOR) in the international ocean sciences community. 